\title{
STUDY OF THE ADMIXTURES EFFECT ON CONCRETE CREEP USING BAYESIAN LINEAR REGRESSION
}

\author{
E. ZGHEIB ${ }^{1}$, W. RAPHAEL ${ }^{2}$
}

\begin{abstract}
Admixtures are commonly used nowadays in the mix composition of concrete. These additions affect concrete properties and performance especially creep deformations. This paper shows the effect of admixtures on creep of concrete. In fact, creep deformations have prejudicial consequences on concrete behaviour; an incorrect or inaccurate prediction leads to undesirable consequences in structures. Therefore, an accurate estimation of these deformations is mandatory. Moreover, design codes do not consider admixtures' effect while predicting creep deformations, thus it is necessary to develop models that predict accurately creep deformations and consider the effect of admixtures. Using a large experimental database coming from international laboratories and research centres, this study aims to update the Eurocode 2 creep model by considering the type and percentage of admixtures using Bayesian Linear Regression method. The effect of two types of admixtures is presented in this paper; the water reducer and silica fume.
\end{abstract}

Keywords: Eurocode 2; concrete creep; Bayesian methods; linearization; admixtures; water reducer; silica fume.

\section{INTRODUCTION}

Concrete has been used since eighteenth century as a primary material in construction. With the evolution in construction field, an improvement in the performance of concrete material became

\footnotetext{
${ }^{1} \mathrm{PhD}$., Saint Joseph University (USJ), Ecole Supérieure d'Ingénieurs de Beyrouth (ESIB), Dekwaneh, Lebanon. Lebanese University, Doctoral School of Sciences and Technology (EDST), Hadath, Lebanon. ORCID ID: 00000003-4296-6607

Current: Lebanese Canadian University, Aintoura, Lebanon. E-mail: elise-zg@hotmail.com; elisezgheib.ez@gmail.com

${ }^{2}$ Prof., Saint Joseph University (USJ), Ecole Supérieure d'Ingénieurs de Beyrouth (ESIB), Dekwaneh, Lebanon. ORCID ID :0000-0002-2960-8760. E-mail: wassim.raphael@usj.edu.lb.
} 
necessary [1]. For this purpose, admixtures and additives are added to the mix composition of concrete to ameliorate its properties and performance $[2,3]$. These additions affect also concrete deformations especially the creep, defined as the time-dependent deformations which reduce the volume of concrete with the impact of external load applied to the concrete element. Since creep deformations have prejudicial consequences on the long-term behavior of structures, it is mandatory to be predicted accurately [4]. But design codes do not consider admixtures effects' while predicting concrete creep, therefore, multiple studies were undertaken in this field. In their study, Gong et al. (2016) have proposed a creep model for a concrete member subjected to axial compression and suffering from sulfate attack [5]. In model B4 [6], the effect of admixture type and percentage is taken into consideration by adding scaling factors to p2, p3, p4 and p5 parameters [7]. Also, Choir et al. (2015), in their study, have proposed a model for the creep phenomenon of hardened cement mixed with expansive additives [8]. As for the Eurocode 2 (EC2), it does not consider the effect of admixtures on creep of concrete, therefore, this study aims at updating it by considering the admixtures' effects, precisely, the water reducer (WR), the silica fume (SF) and the water reducer and silica fume $(\mathrm{WR}+\mathrm{SF})$ added simultaneously to the mix composition of concrete. The water reducer is a chemical admixture that decreases the water content required to achieve a given degree of workability for a concrete mixture. It can be used in normal-,mid-, and figh-range to increase the durability of concrete, primarily by decreasing permeability and improving mechanical properties [9]. Silica fume is added to concrete to improve its properties, particularly, its compressive strength and abrasion resistance. These ameliorations stem from both the mechanical improvements resulting from adding a very fine powder to the cement paste mixture as well as from the pozzolanic reactions between silica fume and the free calcium hydroxide in the paste.

To study the effect of these admixtures, a large experimental database coming from international laboratories and research centers is applied to evaluate the EC2 model [10] by comparing the predicted creep compliance to the experimental measurements using CEB mean deviation and residual methods. An inaccurate estimation of the EC2 creep compliance is noted for all admixtures' types. Therefore, it is mandatory to calibrate the EC2 model by implementing correction coefficients according to the type and percentage of admixtures. Using these correction coefficients will help to predict accurately creep deformations at the design stage for concrete with admixtures and hence, the long-term deflection. These correction coefficients are identified by applying the Bayesian Linear Regression method. 


\section{EUROCODE 2 CREEP EVALUATION}

\subsection{EUROCODE 2 CREEP PREDICTIONS}

According to Eurocode 2 model [11], the compliance function can be predicted using Eq. (1.1):

$$
J\left(t, t_{0}\right)=\frac{1}{E_{c m}\left(t_{0}\right)}+\frac{\varphi\left(t, t_{0}\right)}{E_{c m 28}}
$$

where:

$J\left(t, t_{0}\right)$ - the compliance function, $E_{c m 28}$ and $E_{c m}\left(t_{0}\right)$-the modulus of elasticity of concrete at 28 days after casting and at the loading age $\mathrm{t}_{0}$ respectively, $\Phi\left(\mathrm{t}, \mathrm{t}_{0}\right)$ - the creep coefficient.

This study treats the long-term creep compliance. Therefore, the creep deformations are calculated after 3000 days of applying the external load to the concrete element, it is the time when the creep curves have reached their asymptotic value.

\subsection{EXPERIMENTAL DATABASE}

Rush and Wagner have compiled the first data collection at the Technical University of Munich. This limited database became the basis for the first CEB creep and shrinkage model. Branson and Christiason's paper underlying the 1971 ACI-209 Model, included another collected data.

The first large world-wide creep and shrinkage database was collected at the Northwestern University (NU) by Bažant and Panula [12]. This database established from American and European institutions consisted of approximately 400 creep tests and 300 shrinkage tests and was included in the papers presenting the BP Model [12]. A joint ACI-RILEM committee was organized, during the international ACI Fall 1979 Convention, to extend the Northwestern University database. This work was pursued and led to the RILEM-ACI 209 database in 1992. Some further additions to the database were done, at NU, by Bažant and Li [13] and by Kim [14]. The latest database was assembled at NU during 2010-2013 [10]. Information was extracted from many reports, conference proceedings and journal articles. This database is constituted of approximately 1433 creep tests and 1827 shrinkage tests. The tests in this database are performed using different concrete mix composition (such as: water over cement ratio (w/c); aggregate content (a/c); cement content; aggregate type; admixtures type and percentage; compressive strength; applied stress; specimen geometry) and placed in various environmental conditions (temperature; relative humidity). 


\subsection{EVALUATION METHODS}

To study the accuracy of EC2 compliance predictions using this experimental database, the EC2 compliance is calculated for each test in the database. Then the predicted values are compared to the experimental measurements using the CEB mean deviation $\left(\mathrm{M}_{\mathrm{CEB}}\right)$ and the residual methods.

\subsubsection{THE CEB MEAN DEVIATION $M_{\text {CEB }}$}

The CEB mean deviation method calculates an average gap [15], using the following formulas:

$$
M_{i}=\frac{1}{n} \sum_{j=1}^{n} \frac{\operatorname{CalX}_{i j}}{O b s X_{i j}} \quad \text { and } \quad M_{C E B}=\frac{\sum_{i=1}^{N} M i}{N}
$$

With:

Obs $\mathrm{X}_{\mathrm{ij}}$ - the experimental measurements, Cal $\mathrm{X}_{\mathrm{ij}}$ - the Eurocode 2 creep predictions, $\mathrm{n}$ - the number of measurements for each test, $\mathrm{M}_{\mathrm{i}}$ - the average gap of the $\mathrm{i}^{\text {th }}$ experiment, $\mathrm{N}$ - the total number of tests.

When $\mathrm{M}_{\mathrm{CEB}}$ coefficient is near 1, then the model predict accurately experimental measurements. If $\mathrm{M}_{\mathrm{CEB}}$ exceeds 1, this means that the model overestimates the experimental measurements. Contrary, if the $\mathrm{M}_{\mathrm{CEB}}$ coefficient is less than 1, then the model underestimates experimental measurements.

\subsubsection{THE RESIDUAL METHOD}

The residuals are calculated by the difference between experimental measurements and theoretical predictions, as given in the following equation:

$$
R_{i j}=\left(O b s X_{i j}-C a l X_{i j}\right)
$$

The below graphical representation of residuals versus the observed values shows that the scatters located near the $\mathrm{X}$-axis indicates an accurate estimation since the residual in close to zero. The scatters located below the $\mathrm{X}$-axis indicate that the model overestimates experimental measurements, while the scatters located above the $\mathrm{X}$-axis indicate an underestimation of experimental measurements 


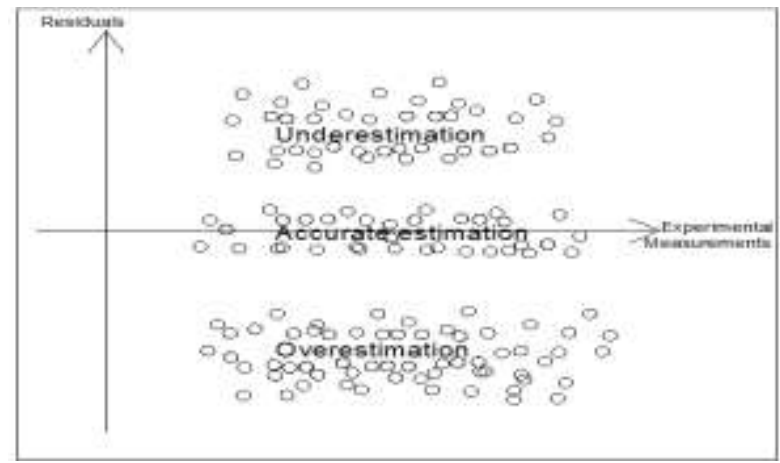

Fig. 1. Residual scatter plot

\subsubsection{RESULTS OF THE EVALUATION OF EUROCODE 2 CREEP MODEL}

These evaluation methods were applied first for concrete without admixtures and have shown that the Eurocode 2 estimates accuratly the creep in this case $\left(\mathrm{M}_{\mathrm{CEB}}=1.09\right)$. Then the effect of admixtures is studied as shown in this paper, where the above evaluation methods were applied to study the accuracy of EC2 model in predicting the compliance function when admixtures, precisely water reducer (WR) and silica fume (SF) are added separately and simultaneously to the concrete mix composition (Table 1).

Table 1. The CEB mean deviation results for concrete creep predictions according to the type of admixture

\begin{tabular}{|c|c|c|}
\hline Eurocode 2 & Admixture Type & $\mathrm{M}_{\mathrm{CEB}}$ (expected value 1) \\
\hline \multirow{3}{*}{$\mathrm{J}\left(\mathrm{t}, \mathrm{t}_{0}\right)$} & Water Reducer $(\mathrm{WR})$ & 0.88 \\
\cline { 2 - 3 } & Silica Fume $(\mathrm{SF})$ & 1.9 \\
\cline { 2 - 3 } & $\mathrm{WR}+\mathrm{SF}$ & 0.86 \\
\hline
\end{tabular}

It can be noticed that EC2 model underestimates creep predictions in the case of concrete with WR and with $\mathrm{WR}+\mathrm{SF}$ since $\mathrm{M}_{\mathrm{CEB}}$ value is less than one (the expected value). Contrary, EC2 model overestimates creep predictions for concrete with SF incorporated in the mix composition. These conclusions are verified in the below residual scatter plots.
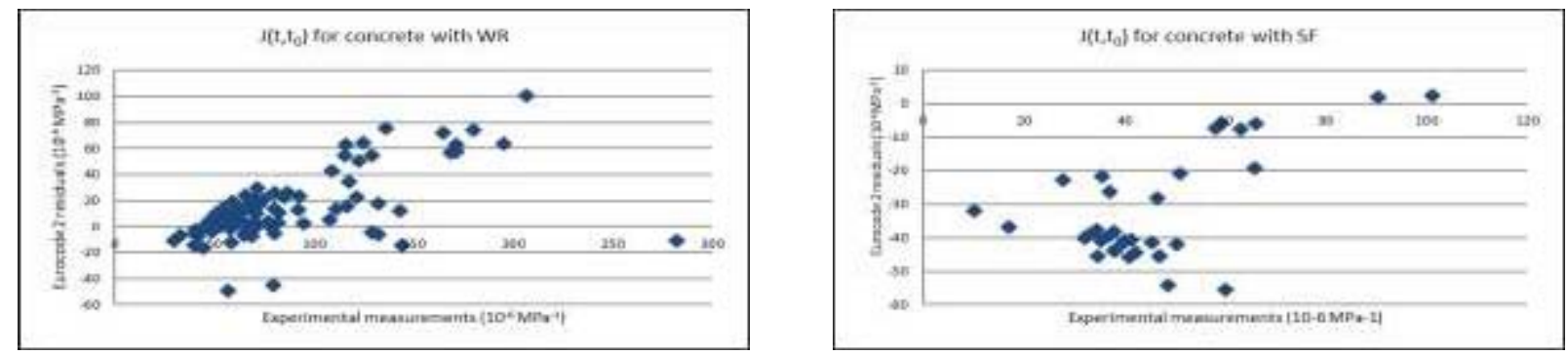


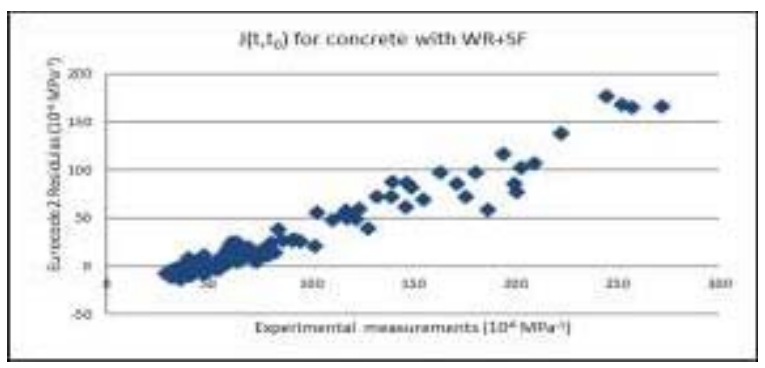

Fig. 2. Residual scatter plot of the EC2 compliance function $J\left(t, t_{0}\right)$ for concrete with water reducer (WR), silica fume (SF) and WR and SF (WR + SF) added simultaneously to the mix composition.

It can be noticed from Fig. 2 that in the case of concrete with WR and with WR + SF, most of the scatters are located above the $\mathrm{X}$-axis showing an underestimation of the compliance function. While, in the case of concrete with SF, all the scatters, except two points, are located below the Xaxis confirming the Eurocode 2 overestimation of the compliance function.

\section{BAYESIAN LINEAR REGRESSION (BLR) METHOD}

To overcome this inaccurate estimation, correction coefficients are implemented in Eurocode 2 formula according to the type and percentage of admixtures as shown in the below equations.

Eq. (3.1) is applied in the case of concrete with WR, while Eq. (3.2) is applied in the case of concrete with SF and Eq. (3.3) in the case of concrete with WR + SF.
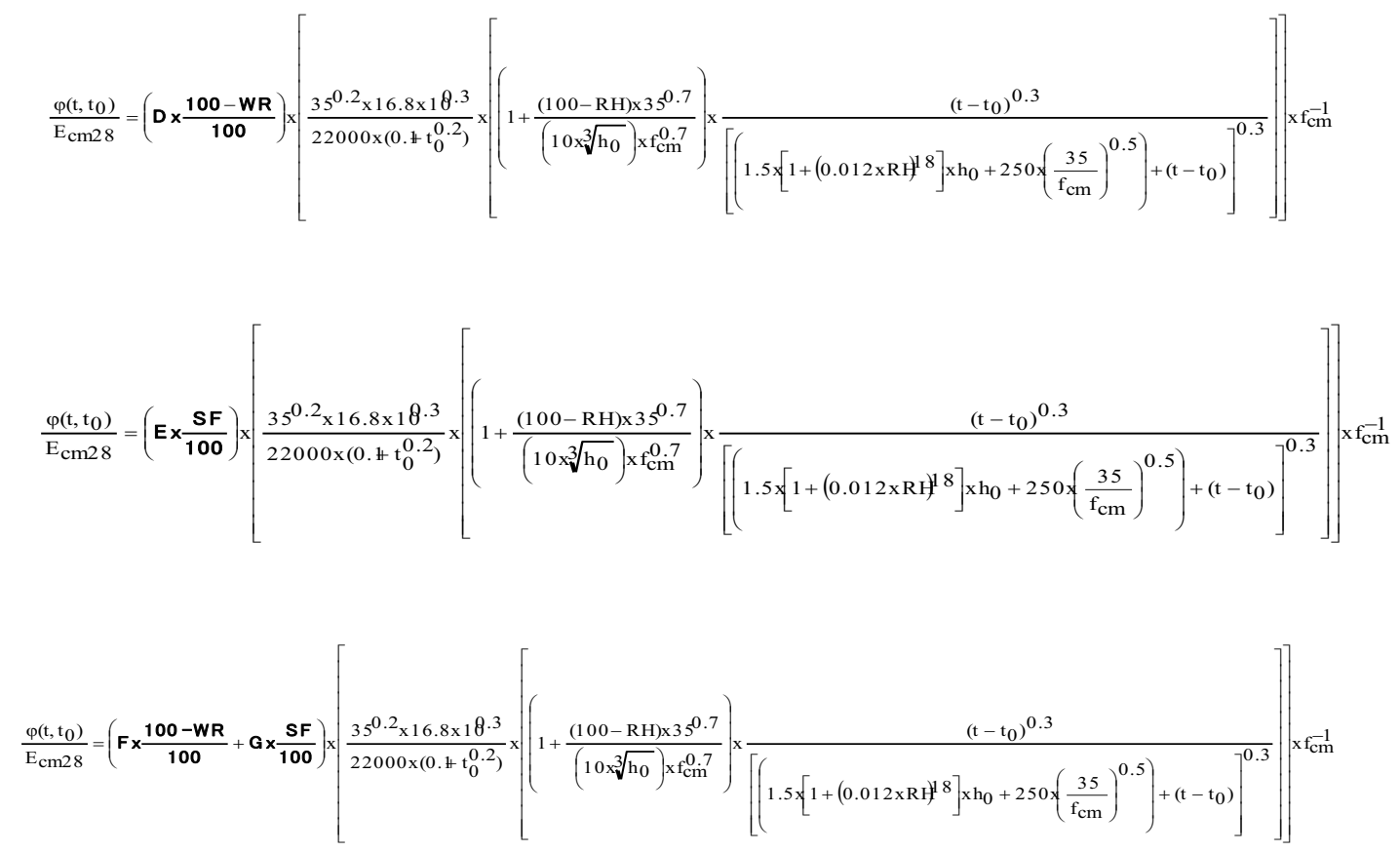
Where:

$\mathrm{D}$ and $\mathrm{E}$ - the correction coefficients added in the case of concrete with water reducer and silica fume added separately to the mix composition, F and G - the correction coefficients implemented in Eurocode 2 formulas in the case of concrete with water reducer and silica fume added simultaneously to the mix composition. WR and SF - the percentage of water reducer and silica fume respectively.

To quantify these correction coefficients, Bayesian inference, which is a way to get sharper predictions from data, is applied in this study. The Bayesian inference consists of multiplying the expert knowledge already known and named as the prior distribution, by the likelihood function coming from the database. Therefore, a posterior distribution is defined which is an update of the knowledge already known using the latest database [16, 17, 18]. More specifically, the Bayesian Linear Regression (BLR) method is applied in this study [19] which is an approach to linear regression in which the statistical analysis is undertaken within the context of Bayesian inference. The detailed procedure and calculations are presented for Eq. (3.1).

To apply the BLR method, a linearization of Eq. (3.1) needs to be established. Therefore, and since the linearization does not affect the results, the logarithmic transformation is applied to Eq. (3.1). Also, by taking the error $\varepsilon_{\mathrm{i}}$ into consideration in calculations, the equation of the $\mathrm{i}^{\text {th }}$ observation is:

$$
\Delta_{\mathrm{i}}=\theta_{1}+\beta_{\mathrm{ai}}+\varepsilon_{\mathrm{i}}
$$

Where:

$$
\begin{aligned}
& \Delta_{i}=\ln \left(\frac{\varphi\left(\mathrm{t}, \mathrm{t}_{0}\right)}{\mathrm{E}_{\mathrm{cm} 28}}\right) ; \theta_{1}=\ln \left(\left(\mathrm{D} \times \frac{100-\mathrm{WR}}{100}\right) x C s t\right) ; \quad \operatorname{Cst}=\left[\frac{35^{0.2} \times 16.8 \times 18.3}{22000 \times\left(0 . \mathrm{t} \mathrm{t}_{0}^{0.2}\right)}\right] \\
& \beta_{a i}=\ln \left(\left[\left(1+\frac{(100-\mathrm{RH}) \times 35^{0.7}}{\left(10 \times \sqrt[3]{\mathrm{h}_{0}}\right) \times \mathrm{f}_{\mathrm{cm}}^{0.7}}\right) \times \frac{\left(\mathrm{t}-\mathrm{t}_{0}\right)^{0.3}}{\left[\left(1.5 \times\left[1+(0.012 \times \mathrm{RH})^{118}\right] \mathrm{xh}_{0}+250 \times\left(\frac{35}{\mathrm{f}_{\mathrm{cm}}}\right)^{0.5}\right)+\left(\mathrm{t}-\mathrm{t}_{0}\right)\right]^{0.3}}\right] x f_{c m}^{-1}\right)
\end{aligned}
$$

By considering that the likelihood is normally distributed with a mean of $\theta_{1}+\beta_{a i}$ and a variance of $\sigma_{\varepsilon}^{2}$, then the likelihood function for $\beta_{\mathrm{a}}$ is: $p\left(\beta_{a} / \theta_{1}\right)=\frac{1}{\sqrt{2 \pi \sigma_{\varepsilon}^{2}}} \exp \left\{\frac{-1}{2 \sigma_{\varepsilon}^{2}} \sum_{i=1}^{n}\left[\Delta_{i}-\left(\theta_{1}+\beta_{a i}\right)\right]^{2}\right\}$ 
Yet the correction coefficient shall be positive since creep compliances are always positive, then the prior of $\theta_{1}$ is normally distributed with a mean of $\mu_{\theta 1}$ and a variance of $\sigma_{\theta 1}{ }^{2}$, and the a priori function for $\theta_{1}$ can be written as: $p\left(\theta_{1}\right)=\frac{1}{\sqrt{2 \pi \sigma_{\theta_{1}}^{2}}} \exp \left\{\frac{-1}{2 \sigma_{\theta_{1}}^{2}}\left(\theta_{1}-\mu \theta 1\right)^{2}\right\}$

By multiplying the likelihood and the prior, the posterior will be equal to:

$$
\mathrm{p}\left(\theta_{1} / \beta_{\mathrm{a}}\right)=\mathrm{p}\left(\beta_{\mathrm{a}} / \theta_{1}\right) \times \mathrm{p}\left(\theta_{1}\right)=\frac{1}{2 \pi \sigma_{\theta_{1}} \sigma_{\varepsilon}} \exp \left\{\frac{-1}{2 \sigma_{\varepsilon}^{2}} \sum_{\mathrm{i}=1}^{\mathrm{n}}\left[\Delta_{\mathrm{i}}-\left(\theta_{1}+\beta_{\mathrm{ai}}\right)\right]^{2}-\frac{1}{2 \sigma_{\theta_{1}}^{2}}\left(\theta_{1}-\mu_{\theta 1}\right)^{2}\right\}
$$

Since the terms outside the exponential are normalizing constants with respect to $\theta_{1}$, they can be dropped. By using some algebra, the posterior can be re-expressed as a normal distribution with mean $\mu_{\theta 1 \mathrm{p}}$ and variance $\sigma_{\theta 1 \mathrm{p}}{ }^{2}$ that can be calculated as follows:

$$
\mu_{\theta 1 p}=\frac{\sigma_{\Theta_{1}}^{2} \sum_{i=1}^{n}\left(\Delta_{i}-\beta_{a i}\right)+\mu_{\theta 1} \sigma_{\varepsilon}^{2}}{n \sigma_{\Theta 1}^{2}+\sigma_{\varepsilon}^{2}} \quad \sigma_{\Theta 1 p}^{2}=\frac{\sigma_{\varepsilon}^{2} \sigma_{\theta 1}^{2}}{n \sigma_{\Theta 1}^{2}+\sigma_{\varepsilon}^{2}}
$$

Knowing $\mu_{\theta 1 \mathrm{p}}$ and since $\theta_{1 \mathrm{p}}=\mu_{\theta 1 \mathrm{p}}$ then the correction coefficient $\mathrm{D}$ is equal to:

$$
\mathrm{D}=\frac{\exp \left(\theta_{1 p}\right)}{\operatorname{Cstx} \frac{100-W R}{100}}
$$

Similarly, the above procedure is applied to Eqs. (3.2)-(3.3) and leads to the following expressions for the correction coefficients:

$$
E=\frac{\exp \left(\theta_{1 p}\right)}{\operatorname{Cstx} \frac{S F}{100}}
$$

$$
\left(F \times\left(\frac{100-W R}{100}\right)+G \times \frac{S F}{100}\right)=\frac{\exp \left(\theta_{1 p}\right)}{C s t}
$$




\section{RESUlts}

To quantify these correction coefficients using the Bayesian Linear Regression (BLR) method, the largest number of tests having the same following properties: age of concrete at loading $\left(\mathrm{t}_{0}\right)$, notional size $\left(\mathrm{h}_{0}\right)$, relative humidity $(\mathrm{RH})$ and duration of loading $\left(\mathrm{t}-\mathrm{t}_{0}\right)$ and with different values for the concrete strength and percentage of admixtures have been selected from the database for each type of admixtures. The results of the application of the BLR method are shown in the following tables.

\subsection{CONCRETE WITH WATER REDUCER (WR)}

Table 2 shows the parameters of the selected tests while Table 3 shows the prior and posterior distribution parameters respectively in the case of concrete with water-reducing admixture.

Table 2. Parameters and constant results for concrete with water-reducing admixture

\begin{tabular}{|c|c|c|c|c|c|}
\hline $\mathrm{n}$ & $\mathrm{t}_{0}$ (days) & $\mathrm{h}_{0}(\mathrm{~mm})$ & $\mathrm{RH}(\%)$ & $\mathrm{t}-\mathrm{t}_{0}$ (days) & Cst \\
\hline 7 & 29 & 44.44 & 99 & 3000 & 0.0015 \\
\hline
\end{tabular}

7 tests were selected from the database to quantify the correction coefficient implemented to EC2 model in the case of concrete with WR admixtures. These specimens with a common notional size of $44.44 \mathrm{~mm}$ are loaded at the age of 29 days. They are maintained in an environment where relative humidity is equal to $99 \%$. Also, this study targets to update the long-term creep which is considered to be equal to 3000 days in this case.

Table 3. Parameters of the prior and posterior distribution and the results of the correction coefficient in the case of concrete with water reducer (WR)

\begin{tabular}{|c|c|c|c|c|}
\hline \multicolumn{2}{|c|}{ Prior parameters } & \multicolumn{2}{|c|}{ Posterior parameters } & Correction coefficient \\
\hline$\mu_{\theta}$ & $\sigma_{\theta}{ }^{2}$ & $\mu_{\theta \mathrm{p}}$ & $\sigma_{\theta \mathrm{p}}{ }^{2}$ & $\mathrm{D}$ \\
\hline-12.2231 & 11.41834 & -6.219 & 0.0285 & 1.35 \\
\hline
\end{tabular}

To evaluate the correction coefficient efficiency, the updated creep compliance is calculated for all tests in database and the results are compared to the experimental measurements using statistical method as shown in the below table. 
Table 4. The CEB mean deviation $\left(\mathrm{M}_{\mathrm{CEB}}\right)$ results for concrete creep predictions before and after correction in the case of concrete with water-reducing admixture

\begin{tabular}{|c|c|}
\hline Concrete with water-reducing admixture & $\mathrm{M}_{\mathrm{CEB}}$ (expected value 1) \\
\hline Before correction & 0.88 \\
\hline After correction $(\mathrm{D}=1.35)$ & 1.05 \\
\hline
\end{tabular}

It can be noticed that after applying the correction coefficient $\mathrm{D}=1.35$, the mean deviation $\mathrm{M}_{\mathrm{CEB}}$ is almost equal to the target value $1\left(\mathrm{M}_{\mathrm{CEB}}=1.05\right)$.
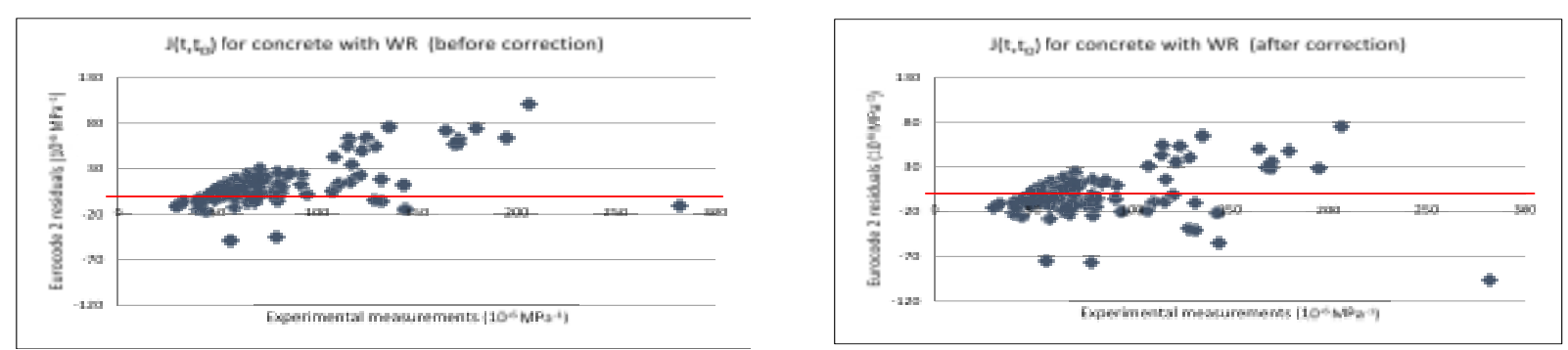

Fig. 3 Residual scatter plot of the Eurocode 2 compliance function $J\left(t, t_{0}\right)$ at long-term for concrete with water reducer (WR) before and after applying the correction coefficient.

The residual scatter plot shows that after applying the correction coefficient, the scatters are distributed equally around the $\mathrm{X}$-axis.

\subsection{CONCRETE WITH SILICA FUME (SF)}

Similarly, Table 5 shows the parameters of the selected tests while Table 6 shows the prior and posterior distribution parameters respectively in the case of concrete with silica fume.

Table 5. Parameters and constant results for concrete with silica fume (SF)

\begin{tabular}{|c|c|c|c|c|c|}
\hline $\mathrm{n}$ & $\mathrm{t}_{0}$ (days) & $\mathrm{h}_{0}(\mathrm{~mm})$ & $\mathrm{RH}(\%)$ & $\mathrm{t}-\mathrm{t}_{0}$ (days) & Cst \\
\hline 12 & 7 & 40 & 70 & 3000 & 0.00196 \\
\hline
\end{tabular}

Since Bayesian Linear Regression method requires constant values for $\mathrm{t}_{0}, \mathrm{~h}_{0}, \mathrm{RH}$ and $\mathrm{t}-\mathrm{t}_{0}$ parameters, 12 tests are selected from the database with constant value for these parameters as shown in Table 5.

Table 6. Parameters of the prior and posterior distribution and the results of the correction coefficient in the case of concrete with silica fume (SF)

\begin{tabular}{|c|c|c|c|c|}
\hline \multicolumn{2}{|c|}{ Prior parameters } & \multicolumn{2}{c|}{ Posterior parameters } & Correction coefficient \\
\hline$\mu_{\theta}$ & $\sigma_{\theta}{ }^{2}$ & $\mu_{\theta \mathrm{p}}$ & $\sigma_{\theta \mathrm{p}}{ }^{2}$ & $\mathrm{E}$ \\
\hline-15.4502 & 14.64544 & -6.4796 & 0.01664 & 5.2 \\
\hline
\end{tabular}


The correction coefficients efficiency evaluation shows that $\mathrm{M}_{\mathrm{CEB}}$ has decreased towards the expected value by adding correction coefficient to EC2 creep compliance for concrete with SF (Table 7).

Table 7. The $\mathrm{CEB}$ mean deviation $\left(\mathrm{M}_{\mathrm{CEB}}\right)$ results for concrete creep predictions before and after correction in the case of concrete with silica fume (SF)

\begin{tabular}{|c|c|}
\hline Concrete with silica fume & $\mathrm{M}_{\mathrm{CEB}}$ (expected value 1) \\
\hline Before correction & 1.9 \\
\hline After correction $(\mathrm{E}=5.2)$ & 1.4 \\
\hline
\end{tabular}

In the case of concrete with SF, the creep can be predicted more accurately by adding the above correction coefficient to the creep compliance formula. It can be noticed from Fig. 4 that after correction the scatters are distributed near the X-axis.
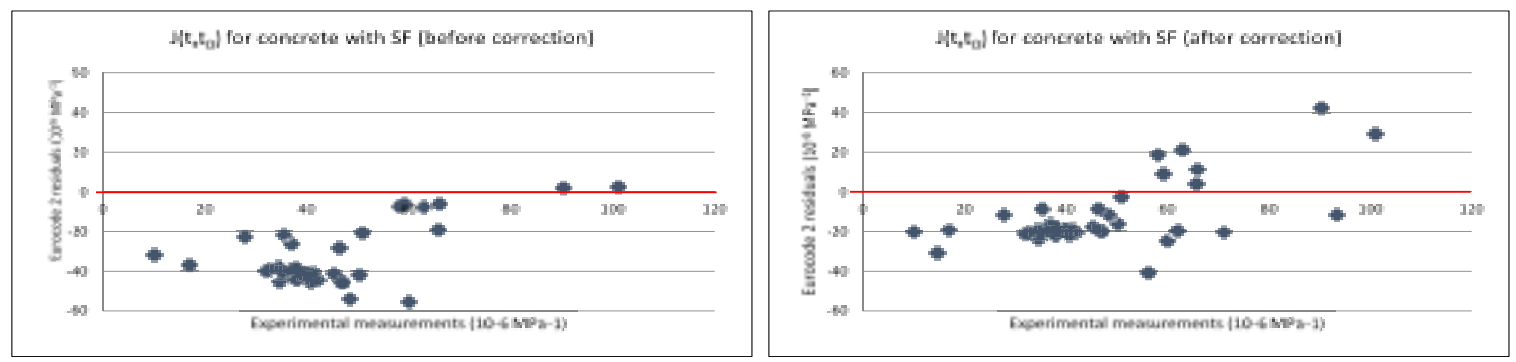

Fig. 4 Residual scatter plot of the Eurocode 2 compliance function $J\left(t, t_{0}\right)$ at long-term for concrete with Silica fume (SF) before and after applying the correction coefficient.

\subsection{CONCRETE WITH WATER REDUCER AND SILICA FUME}

Similarly, Table 8 shows the parameters of the selected tests while Table 9 shows the prior and posterior distribution parameters respectively in the case of concrete with $\mathrm{WR}+\mathrm{SF}$

Table 8. Parameters and constant results for concrete with water reducer (WR) and silica fume (SF)

\begin{tabular}{|c|c|c|c|c|c|}
\hline $\mathrm{n}$ & $\mathrm{t}_{0}($ days $)$ & $\mathrm{h}_{0}(\mathrm{~mm})$ & $\mathrm{RH}(\%)$ & $\mathrm{t}-\mathrm{t}_{0}($ days $)$ & Cst \\
\hline 13 & 28 & 74.08 & 101 & 3000 & 0.001515 \\
\hline
\end{tabular}

13 tests have been selected from the database with constant values for $t_{0}, h_{0}, \mathrm{RH}$ and $\mathrm{t}-\mathrm{t}_{0}$ parameters as shown in Table 8.

Table 9. Parameters of the prior and posterior distribution and the results of the correction coefficients in the case of concrete with water reducer (WR) and silica fume (SF)

\begin{tabular}{|c|c|c|c|c|c|}
\hline \multicolumn{2}{|c|}{ Prior parameters } & \multicolumn{2}{c|}{ Posterior parameters } & \multicolumn{2}{c|}{ Correction coefficients } \\
\hline$\mu_{\theta}$ & $\sigma_{\theta}{ }^{2}$ & $\mu_{\theta \mathrm{p}}$ & $\sigma_{\theta \mathrm{p}}{ }^{2}$ & $\mathrm{~F}$ & $\mathrm{G}$ \\
\hline-11.9798 & 11.17507 & -6.45823 & 0.003076076 & 0.927 & 0.988 \\
\hline
\end{tabular}


The evaluation of the correction coefficients efficiency shows that by adding correction coefficient to EC2 creep compliance for concrete with WR and SF, the mean deviation value has increased towards the target value which is $1\left(\mathrm{M}_{\mathrm{CEB}}=0.98\right)$ as shown in Table 10.

Table 10. The CEB mean deviation $\left(\mathrm{M}_{\mathrm{CEB}}\right)$ results for concrete creep predictions before and after correction in the case of concrete with water reducer (WR) and silica fume (SF)

\begin{tabular}{|c|c|}
\hline Concrete with water reducer and silica fume & $\mathrm{M}_{\mathrm{CEB}}$ (expected value 1) \\
\hline Before correction & 0.86 \\
\hline After correction $(\mathrm{F}=0.93 ; \mathrm{G}=1)$ & 0.98 \\
\hline
\end{tabular}

In the case of concrete with WR $+\mathrm{SF}$, the creep can be predicted more accurately by applying the above correction coefficients to Eurocode 2 formula.
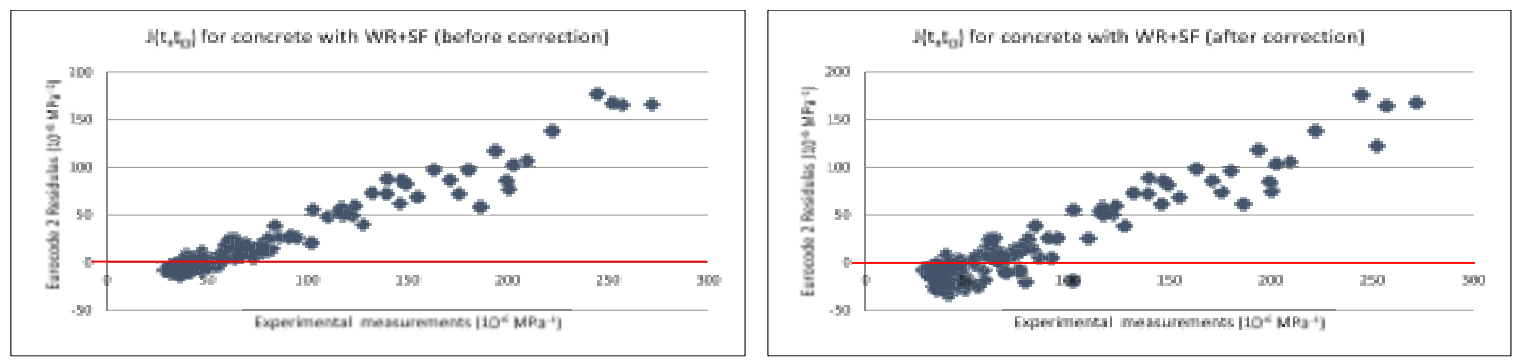

Fig. 5 Residual scatter plot of the EC2 compliance function $J\left(t, t_{0}\right)$ for concrete with Water reducer and Silica fume $(\mathrm{WR}+\mathrm{SF})$ before and after applying the correction coefficient.

\section{Conclusions}

The addition of admixtures to the mix composition of concrete affects its behavior and properties especially creep deformations, the aim of this study. But design codes and specifically Eurocode 2 model does not consider the effect of admixtures while predicting concrete creep. Therefore, correction coefficients are implemented to Eurocode 2 formula to consider the admixtures' effect. These correction coefficients differ according to the type of admixture and take into consideration the percentage of admixtures. In this paper, the Bayesian Linear Regression method is applied to identify these correction coefficients added to the Eurocode 2 compliance formula.

It can be noticed that the implementation of correction coefficients to Eurocode 2 formula allows to predict accurately creep and to consider the effect of admixtures. This study shows that the Bayesian model assessment is an important procedure applied to update the Eurocode 2 creep 
model. The long-term serviceability of structures subject to creep is well improved by adopting such a design approach.

In the future, the Bayesian Linear Regression method may be applied to predict creep for concrete incorporating different types of admixtures and additives other than water reducer and silica fume.

\section{ACKNOWLEDGMENTS}

We would like to acknowledge the National Council for Scientific Research, Lebanon (CNRS-L) and the Research Council of Saint-Joseph University of Beirut for having supported financially this work.

\section{REFERENCES}

1. B. Ranjith Babu, R. Thenmozhi, "An investigation of the mechanical properties of sintered fly ash lightweight aggregate concrete (SFLWAC) with steel fibers", Archives of Civil Engineering LXIV(1): 73-85, 2018.

2. M. Collepardi, "Admixtures used to enhance placing characteristics of concrete", Cement and Concrete Composites 20(2-3): 103-112, 1998.

3. Dr.K.V.S. Gopala Krishna Sastry, A. Ravitheja, Dr.T. Chandra Sekhara Reddy, "Effect of foundry sand and mineral admixtures on mechanical properties of concrete", Archives of Civil Engineering LXIV(1): 117-131, 2018.

4. L. Su, Y. Wang, S. Mei, P. Li, "Experimental investigation on the fundamental behavior of concrete creep", Construction and Building Materials 152: 250-258, 2017

5. J. Gong, J. Cao, Y.-F. Wang, "Effects of sulfate attack and dry-wet circulation on creep of fly-ash slag concrete", Construction and Building Materials 125: 12-20, 2016.

6. Z.P. Bažant, et al., "RILEM draft recommendation: TC-242-MDC multi-decade creep and shrinkage of concrete: material model and structural analysis. Model B4 for creep, drying shrinkage and autogenous shrinkage of normal and high-strength concretes with multi-decade applicability", Materials and Structures 48: 753-770, 2015. Available at: http://link.springer.com/10.1617/s11527-014-0485-2.

7. M.H. Hubler, R. Wendner, Z.P. Bažant, "Statistical justification of Model B4 for Multi-Decade concrete creep using laboratory and bridge databases and comparisons to other models", Materials and Structures 48(4): 815$833,2015$.

8. H. Choi, M. Lim, H. Choi, T. Noguchi, R. Kitagaki, "Modelling of creep of concrete mixed with expansive additives", Magazine of concrete research 67(7): 335-348, 2015.

9. K.C. Hover, „Concrete mixture proportioning with water-reducing admixtures to enhance durability: A quantitative model", Cement and Concrete Composites 20(2-3): 113-119, 1998.

10. M.H. Hubler, R. Wendner, Z.P. Bažant, "Comprehensive database for concrete creep and shrinkage: analysis and recommendations for testing and recording", American Concrete Institute Materials Journal 112(4): 547$558,2015$.

11. Eurocode 2: Design of Concrete Structures - Part 1-1: General Rules and Rules for Buildings, European Committee for Standardization, Brussels, Belgium, 2004.

12. Z. Bažant, L. Panula, "Practical prediction of time dependent deformations of concrete", Matériaux et Construction 11(5): 307-316, 317-328, 415-424, 425-434, 1978.

13. Z. Bažant, G. Li, "Comprehensive Database on concrete creep and shrinkage", American Concrete Institute Materials Journal 105(6): 635-638, 2008.

14. K. Kim, "Creep-database V1.1" 2010, www.iti.northwestern.edu/publications/bazant/

15. ACI 209.2R-08: Guide for Modelling and Calculating Shrinkage and Creep in Hardened Concrete, American Concrete Institute, Farmington Hills, MI, U.S.A, 2008. 
16. G. Box, G. Tiao, Bayesian Inference in Statistical Analysis, Wiley-Interscience Publication, John Wiley and Sons, Inc, Hoboken, NJ, 1992.

17. M. Riddle, R.T. Muehleisen, "A guide to Bayesian calibration of building energy models", In Building Simulation Conference, Atlanta, GA, 2014.

18. Y. Heo, R. Choudhary, G.A. Augenbroe, "Calibration of building energy models for retrofit analysis under uncertainty", Energy and Buildings 47: 550-560, 2012.

19. W.M. Bolstad, J.M. Curran, Introduction to Bayesian Statistics, $3^{\text {rd }}$ edition, John Wiley, 2016.

\section{LIST OF FIGURES AND TABLES:}

Fig. 1. Residual scatter plot

Tab. 1. The CEB mean deviation results for concrete creep predictions according to the type of admixture

Fig. 2. Residual scatter plot of the EC2 compliance function $J(t, t 0)$ for concrete with water reducer (WR), silica fume (SF) and WR and SF (WR + SF) added simultaneously to the mix composition.

Tab. 2. Parameters and constant results for concrete with water-reducing admixture

Tab. 3. Parameters of the prior and posterior distribution and the results of the correction coefficient in the case of concrete with water reducer (WR)

Tab. 4. The CEB mean deviation (MCEB) results for concrete creep predictions before and after correction in the case of concrete with water-reducing admixture

Fig. 3 Residual scatter plot of the Eurocode 2 compliance function $J(t, t 0)$ at long-term for concrete with Water reducer (WR) before and after applying the correction coefficient.

Tab. 5. Parameters and constant results for concrete with silica fume (SF)

Tab. 6. Parameters of the prior and posterior distribution and the results of the correction coefficient in the case of concrete with silica fume (SF)

Tab. 7. The CEB mean deviation (MCEB) results for concrete creep predictions before and after correction in the case of concrete with silica fume (SF)

Fig. 4. Residual scatter plot of the Eurocode 2 compliance function $J(t, t 0)$ at long-term for concrete with Silica fume (SF) before and after applying the correction coefficient.

Tab. 8. Parameters and constant results for concrete with water reducer (WR) and silica fume (SF)

Tab. 9. Parameters of the prior and posterior distribution and the results of the correction coefficients in the case of concrete with water reducer (WR) and silica fume (SF)

Tab. 10. The CEB mean deviation (MCEB) results for concrete creep predictions before and after correction in the case of concrete with water reducer (WR) and silica fume (SF)

Fig. 5 Residual scatter plot of the EC2 compliance function $J\left(t, t_{0}\right)$ for concrete with Water reducer and Silica fume (WR+SF) before and after applying the correction coefficient. 